\title{
Article
}

\section{Genetic Variants of Alcohol Metabolizing Enzymes and Alcohol-Related Liver Cirrhosis Risk}

\author{
Pedro Ayuso ${ }^{1, *}$, Elena García-Martín ${ }^{1}$, José A. Cornejo-García ${ }^{2}$, José A. G. Agúndez ${ }^{1}$ and José María Ladero ${ }^{3}$ \\ 1 ARADyAL, Instituto de Salud Carlos III, University Institute of Molecular Pathology Biomarkers, UEx, \\ 10003 Cáceres, Spain; elenag@unex.es (E.G.-M.); jagundez@unex.es (J.A.G.A.) \\ 2 ARADyAL, Instituto de Salud Carlos III Research Laboratory, IBIMA, Regional University Hospital of \\ Málaga, UMA, 29010 Málaga, Spain; josea.cornejo@gmail.com \\ 3 Service of Gastroenterology (Liver Unit), Hospital Clínico San Carlos, Universidad Complutense Medical \\ School, 28040 Madrid, Spain; jladeroq@gmail.com \\ * Correspondence: payupar@unex.es
}

check for updates

Citation: Ayuso, P.; García-Martín,

E.; Cornejo-García, J.A.; Agúndez,

J.A.G.; Ladero, J.M. Genetic Variants of Alcohol Metabolizing Enzymes and Alcohol-Related Liver Cirrhosis Risk. J. Pers. Med. 2021, 11, 409.

https://doi.org/10.3390/jpm11050409

Academic Editor: Lorenza Rimassa

Received: 8 March 2021

Accepted: 9 May 2021

Published: 13 May 2021

Publisher's Note: MDPI stays neutral with regard to jurisdictional claims in published maps and institutional affiliations.
Abstract: Alcohol-related liver disease (ARLD) is a major public health issue caused by excessive alcohol consumption. ARLD encompasses a wide range of chronic liver lesions, alcohol-related liver cirrhosis being the most severe and harmful state. Variations in the genes encoding the enzymes, which play an active role in ethanol metabolism, might influence alcohol exposure and hence be considered as risk factors of developing cirrhosis. We conducted a case-control study in which 164 alcohol-related liver cirrhosis patients and 272 healthy controls were genotyped for the following functional single nucleotide variations (SNVs): $A D H 1 B$ gene, rs1229984, rs1041969, rs6413413, and rs2066702; ADH1C gene, rs35385902, rs283413, rs34195308, rs1693482, and rs35719513; CYP2E1 gene, rs3813867. Furthermore, copy number variations (CNVs) for ADH1A, ADH1B, ADH1C, and CYP2E1 genes were analyzed. A significant protective association with the risk of developing alcohol-related liver cirrhosis was observed between the mutant alleles of SNVs $A D H 1 B$ rs1229984 $\left(P_{c}\right.$ value $\left.=0.037\right)$ and $A D H 1 C$ rs283413 $\left(P_{c}\right.$ value $\left.=0.037\right)$. We identified $C N V s$ in all genes studied, $A D H 1 A$ gene deletions being more common in alcohol-related liver cirrhosis patients than in control subjects, although the association lost statistical significance after multivariate analyses. Our findings support that susceptibility to alcohol-related liver cirrhosis is related to variations in alcohol metabolism genes.

Keywords: alcohol-related liver disease; cirrhosis; single nucleotide variations; copy number variations; alcohol dehydrogenase

\section{Introduction}

Alcohol consumption is a common habit that varies considerably by location [1] Recent data of the prevalence of Spanish current drinkers indicate that $55 \%$ of females and $78 \%$ of males were current drinkers, which is much higher than global data $(25 \%$ of females and $39 \%$ of males) [1]. Excessive alcohol consumption is associated with a wide range of problems relating to physical health, either directly, or through contributions to other health conditions. Consequently, the associated health problems have reached alarming levels, becoming a major public health concern. In 2016, more than 3 million deaths were attributed to alcohol consumption, which represents 1 in 20 deaths worldwide [2]. Excessive alcohol consumption evokes a wide spectrum of hepatic lesions. Steatosis is the earliest and commonest liver disease, which is reversible if the affected individual ceases drinking [3]. However, patients with chronic steatosis are more susceptible to fibrotic liver diseases and $10-20 \%$ of heavy drinkers develop the terminal or late stage cirrhosis, which is characterized by excessive liver scarring, vascular alterations, architectural distortion, and eventual liver failure [4].

There is considerable variability in the susceptibility of developing cirrhosis on an individual basis. These determinants reflect the interplay of constitutional and environmental factors. Also, variations in the genes encoding the enzymes playing an active role 
in ethanol metabolism might be considered as risk factors to develop cirrhosis because impaired ethanol metabolism increases body exposure [5].

Ethanol is predominantly metabolized in the liver, where two different enzymatic systems have been characterized [6]. These are alcohol dehydrogenase (ADH; EC 1.1.1.1) and the microsomal ethanol-oxidizing system (MEOS) [7]. Hepatic ADH consists of five enzyme classes, ADH1 through ADH5. For class I, three subunits $\alpha, \beta$, and $\gamma$, have been described. The different isoenzymes primarily involved in hepatic ethanol metabolism are homo- and hetero-dimeric molecules, whose subunits are encoded by $A D H 1 A, A D H 1 B$, and $A D H 1 C$ genes. These isoenzymes catalyze the oxidation and reduction of a wide variety of alcohols into acetaldehydes, with differences in their properties [8]. Subsequently, acetaldehyde is converted by aldehyde dehydrogenases (ALDH; EC 1.2.1.3) to acetate [9]. It is estimated that class I enzymes might contribute to $\sim 70 \%$ of the total ethanol oxidizing capacity in the liver [10].

Environmental factors, such as alcohol consumption or concomitant diseases, determine the ARLD progression and the occurrence of alcohol-related liver cirrhosis. Nevertheless, there are interindividual differences in these patients that may not be completely explained by these factors [11]. Thereby, the contribution of genetic factors in ARLDs development has been extensively studied. Substantial interest has been focused on the study of associations between ARLD and variants in genes involved in ethanol metabolism, lipid metabolism, oxidative stress, or immune response [12]. Thus, the variant rs738409 in patatin-like phospholipase domain-containing 3 (PNPLA3) has been identified as a risk factor for suffering alcohol-related liver cirrhosis $[5,13,14]$ and non-alcoholic fatty liver disease (NAFLD) [15]. PNPLA3 is a triacylglycerol lipase involved in lipolytic and lipogenic processes [12,16]. Nevertheless, the functional implication of this association has not been completely elucidated. Thus, different studies have demonstrated that the rs738409 PNPLA3 mutant variant may cause gain [17] or loss of function [18]. In addition, a genome-wide association study also identified two additional gene loci related to lipid metabolism, MBOAT7 and TM6SF2, as risk factor for developing alcohol-related liver cirrhosis [19]. Although these associations are less robust in comparison to that of PNPLA3, these variants in genes involved in lipid metabolism, oxidative stress or immune response have been demonstrated to be risk factors both for ARLD and NAFLD [12].

Concerning genes involved in ethanol metabolism, single nucleotide variations (SNVs) are common in ADH1 genes [20]. These SNVs are associated with changes in enzyme kinetics, which affect production and removal of the toxic metabolite acetaldehyde [21]. These alterations in alcohol pharmacokinetics caused by these SNVs may influence ARLD risk [5]. Thus, it has been shown that the variant rs1229984 in $A D H 1 B$, which is relatively common among Asians and rarer in Europeans, plays a protective role against alcohol use disorders [5].

The second enzymatic system, MEOS, consists of cytochrome P450, NADPH-cytochrome p450 reductase, and phospholipids. Its activity depends strongly on cytochrome P450 enzymes, predominantly CYP2E1 [8]. CYP2E1 accounts for 20-25\% of the alcohol metabolism in vivo [22]. CYP2E1 can be induced by high alcohol levels and following chronic alcohol abuse [23]. The gene variant CYP2E1*5B, conformed by two SNVs in close linkage disequilibrium that are placed in the 5 'flanking region, modifies the transcriptional activity of this gene [24]. This genetic variant has been associated with ARLD in the Asian population [25-27], although this association has not been consistently replicated in Caucasians, probably because of the 10-fold lower frequency of the corresponding SNVs in Caucasian individuals, as compared to individuals with Asian descent [28-31].

Although most of these above-mentioned studies have been focused on SNVs, there is an increasing interest in gene copy number variations (CNVs) as an additional source of genetic variability. CNVs are structural variations in the DNA sequence consisting of excess or deficiency of sections of DNA sequence [32]. Since these CNVs affect large gene fragments, or the whole gene, their functional consequences are huge. Currently, several studies have analyzed the association between CNVs and alcohol dependence [33-35]. 
Nevertheless, to our best knowledge, no studies analyzing CNVs in genes involved in alcohol biodisposition in alcoholic cirrhosis have been carried out.

Aiming to identify genetic susceptibility factors for the development of alcohol-related liver cirrhosis that could be related to ethanol biodisposition, we analyzed the frequency of $A D H 1 A, A D H 1 B, A D H 1 C$, and CYP2E1 genetic variants, both SNVs and CNVs, in a well-characterized cohort of Spanish patients.

\section{Materials and Methods}

\subsection{Human Subject Cohort}

A case-control study was designated to investigate the association of functional SNVs and CNVs in the ADH1A, ADH1B, ADH1C, and CYP2E1 genes, with alcohol-related liver cirrhosis. The study included 164 Caucasian Spanish patients with alcohol-related liver cirrhosis and 272 Caucasian Spanish healthy individuals who were recruited at the San Carlos University Hospital (Madrid, Spain) and the University Hospital Infanta Cristina (Badajoz, Spain). Controls were recruited among students and staff. Demographic data, clinical characteristics, and drinking habits were collected for all participants. Table 1 summarizes the characteristics of participants. Concerning healthy individuals, the inclusion criteria were the following: none had personal antecedents of alcoholism or reported familial antecedents of alcoholism, age over 18, absence of consumption of illicit drugs by self-report, and lack of exclusion criteria. As well, the exclusion criteria for healthy individuals were pregnancy, diabetes mellitus, history of gastrointestinal, liver, or renal disease.

Table 1. Characteristics of individuals included in the study.

\begin{tabular}{cccc}
\hline Variable & Cirrhosis Patients $\mathbf{( N = 1 6 4 )}$ & Controls $(\mathbf{N}=\mathbf{2 7 2})$ & $p$-Value \\
\hline Age (mean \pm SD), years & $55.83 \pm 10.32$ & $23.67 \pm 7.38$ & 0.000 \\
\hline Sex (male/female) & $145 / 19$ & $81 / 191$ & 0.000 \\
\hline $\begin{array}{c}\text { Alcohol consumption } \\
\text { (mean } \pm \text { SD), g/day }\end{array}$ & $129.24 \pm 62.72$ & $2.14 \pm 5.34$ & 0.000 \\
\hline
\end{tabular}

For patients, the inclusion criteria were the following: All patients had advanced decompensated ARLD and had consumed at least $100 \mathrm{~g}$ of ethanol daily for at least 10 years. Patients were diagnosed based on their liver biopsy. All of them had ultrasonographic patterns compatible with liver cirrhosis and signs of portal hypertension. In addition, the exclusion criteria for patients were the following features: (a) negative results for hepatitis $B$ virus surface antigen and for hepatitis $C$ virus antibodies in serum were prerequisites for their inclusion in the study; (b) absence of other liver disease (autoimmune, metabolic, toxic or drug-induced). All participants were previously informed and gave their informed consent to participate. The protocol for this study was in accordance with the Declaration of Helsinki and its subsequent revisions and was approved by the Ethics Committee of the participating hospitals, University Hospital Infanta Cristina (Badajoz, Spain) and San Carlos University Hospital (Madrid, Spain). Some participants in this study participated in previous studies by our group [36-41].

\subsection{Blood Samples and Genotyping}

A $10 \mathrm{~mL}$ sample of blood was drawn in an EDTA vacutainer by venopuncture and kept at $-80{ }^{\circ} \mathrm{C}$ until analyzed. Genomic DNA was extracted from peripheral leukocytes and dissolved in sterile $10 \mathrm{mM}$ Tris $\mathrm{HCl}, \mathrm{pH} 8.0,1 \mathrm{mM}$ ethylenediaminetetraacetic acid at a final concentration of $400-600 \mu \mathrm{g} / \mathrm{mL}$.

The SNVs and CNVs tested, selected because of their allele frequencies in the population studied and their expected effect in enzyme activity, are described in Table 2. Genotyping was carried out by using TaqMan assays (Life technologies, Alcobendas, Madrid, Spain), which were designed to detect the previously mentioned SNVs. Detection was carried out in by real-time quantitative polymerase chain reaction in an Applied 
Biosystems 7500 real-time thermocycler as described by the manufacturer. Full details of the procedure were described previously [42]. All samples were determined in triplicate. Genotypes were assigned by using the gene identification software (7500 software 2.0.3 Applied Biosystems, Foster City, CA, USA) and by analysis of the reference cycle number for each fluorescence curve.

Table 2. Selection of SNVs and CNVs genotyped.

\begin{tabular}{ccc}
\hline Gene & Variant & Consequence \\
\hline$A D H 1 B$ & CNV & Deletion/Duplication \\
\hline$A D H 1 B$ & rs1229984 & His48Arg \\
\hline$A D H 1 B$ & rs1041969 & Asn57Lys \\
\hline$A D H 1 B$ & rs6413413 & Thr60Ser \\
\hline$A D H 1 B$ & rs2066702 & Arg370Cys \\
\hline$A D H 1 B$ & CNV & Deletion/Duplication \\
\hline$A D H 1 C$ & rs35385902 & Gly78X \\
\hline$A D H 1 C$ & rs283413 & Pro166Ser \\
\hline$A D H 1 C$ & rs34195308 & Arg272Gln \\
\hline$A D H 1 C$ & rs1693482 & Pro352Thr \\
\hline$A D H 1 C$ & rs35719513 & Deletion/Duplication \\
\hline$A D H 1 C$ & $\mathrm{CNV}$ & Upstream in promoter region \\
\hline$C Y P 2 E 1$ & rs3813867 & Deletion/Duplication \\
\hline$C Y P 2 E 1$ & CNV &
\end{tabular}

CNVs were analyzed by using the TaqMan copy number assays of the $A D H 1 A$ and ADH1B, ADH1C and CYP2E1 genes, Hs00293646_cn, Hs03076708_cn Hs05919789_cn and Hs00231786_cn, respectively. The procedure was described previously [42]. All assays were designed to hybridize within the open reading frame within the target genes (Life technologies, Alcobendas, Madrid, Spain). The amplification was carried out in an Applied Biosystems 7500 real-time thermocycler as described by the manufacturer, using RNAase $P$ as a copy number reference assay. All reactions were carried out in quadruplicate. Results were analyzed by means of the CopyCaller Software v1.0 (Applied Biosytems, Foster City, CA, USA ) [42]. According to standard procedures in CNV analyses, samples with a single copy of the corresponding gene were named as heterozygous (null/present). Because the probes were designed to detect exonic sequences, even if the rest of the gene would remain intact in these so-called null alleles, the translated protein would not be functional [42].

\subsection{Statistical Analysis}

The descriptive analysis of the different variables analyzed was performed by means of absolute frequencies for categorical variables and mean and standard deviation (SD) for continuous variables using the SPSS 22.0 statistical package (SPSS Inc., Chicago, IL, USA). Kolmogorov-Smirnoff test was used to check normality in the distribution. Then, the Student two-sample $t$ test or the Mann-Whitney test were used for continuous variables. The Hardy-Weinberg equilibrium and the linkage disequilibrium analyses were performed with the PLINK v1.07 software (Broad Institute of Harvard \& MIT, Cambridge, MA, USA) [43]. The comparison between groups was performed with the Chi-square test and Likelihood ratio test, with an initial crude analysis followed by an adjusted analysis including gender and age as categorical variables. A univariate analysis through logistic enter regression was used to identify independent variables associated with alcohol-related liver cirrhosis. Those variables with a $p$ value $\leq 0.05$ for the univariate analysis were carried out through to a stepwise logistic multivariate regression. A multivariate analysis through 
logistic regression using gender and age as covariates was carried out to determine the association of genetic variants, isolated or grouped in haplotypes, and alcohol-related liver cirrhosis status. Adjustments for multiple analyses were performed by using the False Discovery Rate correction. $P_{c}$ values $\leq 0.05$ were considered statistically significant. The association between genetic variants and alcohol-related liver cirrhosis trait was estimated by odds ratio (OR) with a 95\% confidence interval (CI) [43].

\subsection{Availability of Materials and Data}

The datasets generated during and/or analyzed during the current study are available from the corresponding author on reasonable request.

\section{Results}

The detailed characteristics of the subjects included in this study are summarized in Table 1. The mean age of alcohol-related liver cirrhosis patients was higher in comparison to healthy subjects, and gender distribution was dissimilar between both groups. This is attributable to the lesser prevalence of alcohol-related liver cirrhosis in women compared to men [44]. However, age is not a relevant factor in allele frequencies, nor is gender as none of the genes studied are located either in $\mathrm{X}$ or $\mathrm{Y}$ chromosomes. The genotype distribution for all genetic variants tested in both healthy subjects and alcohol-related liver cirrhosis patients was in Hardy-Weinberg's equilibrium.

The genotype frequencies of the variants examined in the study are shown in Table 3. Considering $A D H 1 B$, two of the polymorphisms analyzed, rs1041969 Asn57Lys and rs2066702 Arg370Cys, were monomorphic in both cohorts of subjects. In addition, we identified the variant alleles $A D H 1 B^{*} 1(\operatorname{Arg} 48+\operatorname{Arg} 370)$ and $A D H 1 B^{*} 2(\mathrm{His} 48+\operatorname{Arg} 370)$. Furthermore, heterozygous individuals for the SNV rs6413413 Thr60Ser were identified in both healthy subjects and cirrhosis patients.

Regarding ADH1C, three polymorphisms, rs35385902 Arg48His, rs34195308 Pro166Ser, and rs35719513 Pro352Thr, were monomorphic in our study population. Although a low frequency was expected in control individuals, no previous studies analyzed these variants in Caucasian alcohol-related liver cirrhosis patients. The $A D H 1 C$ gene has two major allelic variants, $A D H 1 C^{*} 1$ (Arg272 + Ile350) and $A D H 1 C^{*} 2$ (Glu272 + Val350). The SNVs responsible for these amino acid substitutions are at a very high linkage disequilibrium [45]. Accordingly, we genotyped the SNV rs1693482 Arg272Glu. The allelic frequency displayed in our study population is in keeping with previous studies in European populations [46].

The results of genotype frequencies observed in individuals stratified by the CYP2E1 genotype are shown in Table 3.

We found that the frequency of the mutated form of the SNVs ADH1B rs1229984 and $A D H 1 C$ rs 283413 were significantly lower in alcohol-related liver cirrhosis patients. Concerning $A D H 1 B$ rs1229984, the adjusted $p$ value was equal to 0.008 . Regarding $A D H 1 C$ rs283413, the adjusted $p$ value was equal to $=0.015$. For both SNVs, the statistically significant differences remained after FDR adjustment for multiple comparisons (Table 3).

$\mathrm{CNV}$ analyses revealed that structural variations for the $A D H 1 A, A D H 1 B, A D H 1 C$, and CYP2E1 genes occur in Caucasian individuals. The results obtained are shown in Table 3. Overall findings indicate that $A D H 1 A$ CNVs (in all cases deletions) occur in $1.8 \%$ of individuals, being more frequent in alcohol-related liver cirrhosis patients (crude $p$ value $=0.013, P_{c}=0.944$ ). For $A D H 1 B$, we identified a single case of a patient with three gene copies, whereas the rest of patients and control individuals carried two copies. For $A D H 1 C$, we only identified individuals with one or two copies, being less frequent the presence of a single copy in patients with alcohol-related liver cirrhosis, although the differences were not statistically significant, as shown in Table 3. For CYP2E1, we identified healthy individuals with one, two, or three copies, whereas all patients with cirrhosis carried two copies of the gene. 
Table 3. Distribution of genotype frequencies of $A D H 1, A D H 2, A D H 3$, and $C Y P 2 E 1$ genetic variants.

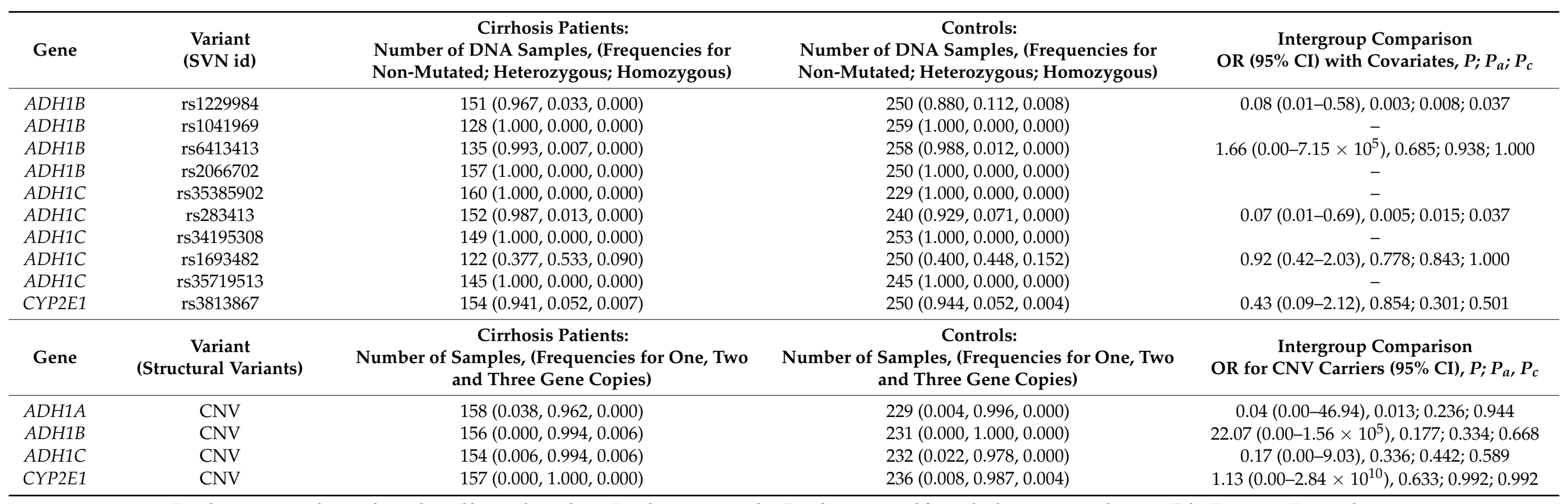

$P_{a}$ values correspond to $p$ values adjusted by gender and age. $P_{c}$ values correspond to $P_{a}$ values corrected for multiple comparisons by using False Discovery. Rate analyses. 
Univariate and multivariate regression analysis for alcohol-related liver cirrhosis status based on $A D H 1 A, A D H 1 B, A D H 1 C$, and CYP2E1 genetic variants are presented in Table 4. After multivariate logistic analysis, the SNVs $A D H 1 B$ rs1229984 ( $p$ value $=0.023$, $\beta=0.01$ ) remained associated with the risk of developing alcohol-related liver cirrhosis.

Table 4. Univariate and multivariate logistic regression analysis.

\begin{tabular}{|c|c|c|c|c|c|c|c|}
\hline \multirow[b]{2}{*}{ Gene } & \multirow[b]{2}{*}{ Variant (SVN Id) } & \multicolumn{3}{|c|}{ Univariate Logistic Regression } & \multicolumn{3}{|c|}{ Multivariate Logistic Regression } \\
\hline & & $p$ Value & $\beta$ Value $(95 \% \mathrm{CI})$ & B & $p$ Value & $\beta$ Value $(95 \% \mathrm{CI})$ & B \\
\hline$A D H 1 A$ & $\mathrm{CNV}$ & 0.043 & $0.11(0.01-0.93)$ & -2.20 & 0.924 & & - \\
\hline$A D H 1 B$ & rs1229984 & 0.012 & $0.31(0.12-0.77)$ & -1.18 & 0.023 & $0.01(0.13-0.72)$ & -2.34 \\
\hline$A D H 1 B$ & rs6413413 & 0.695 & $0.63(0.06-6.16)$ & -0.45 & & & \\
\hline$A D H 1 B$ & $\mathrm{CNV}$ & 1.0 & - & - & & & \\
\hline$A D H 1 C$ & rs283413 & 0.021 & $0.175(0.04-0.77)$ & -1.74 & 0.090 & & \\
\hline$A D H 1 C$ & rs1693482 & 0.788 & $1.04(0.76-1.43)$ & 0.043 & & & \\
\hline ADH1C & $\mathrm{CNV}$ & 0.377 & $2.70(0.30-24.35)$ & 0.992 & & & \\
\hline CYP2E1 & rs3813867 & 1.0 & - & - & & & \\
\hline CYP2E1 & $\mathrm{CNV}$ & 0.641 & $1.79(0.15-20.55)$ & 0.581 & & & \\
\hline Sex & - & $<0.001$ & $17.99(10.44-31.01)$ & 2.89 & $<0.001$ & $13.38(3.98-44.95)$ & 2.59 \\
\hline Age & - & $<0.001$ & 1.27 (1.21-1.33) & 0.24 & $<0.001$ & 1.25 (1.18-1.33) & 0.23 \\
\hline
\end{tabular}

Univariate logistic regression $(p \leq 0.2)$ completed; all statistically significant results then carried through to a stepwise. Logistic multivariate regression analysis $(p \leq 0.05)$. All statistically significant variables from multivariate logistic regression shown in bold type.

We also investigated the putative effect of haplotypes characterized by the combination of $A D H 1 B$ rs $1229984+$ rs6413413, and ADH1C rs283413 + rs1693482 SNVs. Thirty-one haplotypes were observed in alcohol-related liver cirrhosis patients and healthy individuals (Table 5). Haplotypes that show a significant association and a risk effect for developing alcohol-related liver cirrhosis are those composed of the alleles that also revealed a significant association in single-SNV analyses, thus suggesting that the risk is attributable to the $\mathrm{SNVs}$ isolated, rather than to the haplotypes. However, we observed that the combination of the wild type genotype of two SNVs, namely ADH1B rs1229984 and ADH1C rs283413, was significantly higher in alcohol-related liver cirrhosis individuals when compared with healthy subjects $\left(\mathrm{OR}=6.92, P_{a}=0.018, P_{c}=0.078\right)$. In addition, the $\mathrm{OR}$ associated was higher than that associated with each SNV analyzed separately. This result is keeping in line with the observed protective role of the mutant alleles of both SNVs. However, the association described between this haplotype and the susceptibility for developing alcohol-related liver cirrhosis was found to be non-significant after multiple testing correction. 
Table 5. Alcohol dehydrogenase haplotypes in patients with alcoholic liver cirrhosis and healthy controls.

\begin{tabular}{|c|c|c|c|c|}
\hline $\begin{array}{c}\text { Haplotype } \\
\text { Variant (SVN Id) }\end{array}$ & Genotype & $\begin{array}{c}\text { Cirrhosis Patients: } \\
\text { Number of Total DNA Samples, } \\
\text { (Frequency for Haplotype) }\end{array}$ & $\begin{array}{c}\text { Controls: } \\
\text { Number of Total DNA Samples, } \\
\text { (Frequency for Haplotype) }\end{array}$ & $\begin{array}{l}\text { Haplotype Association Analysis } \\
\text { OR }\left(95 \% \text { CI), } P ; P_{a} ; P_{c}\right.\end{array}$ \\
\hline rs1229984-rs6413413-rs283413-rs1693482 & A-A-G-A & $108(0.349)$ & $228(0.332)$ & $1.09(0.48-2.49), 0.464 ; 0.838 ; 0.690$ \\
\hline rs1229984-rs6413413-rs283413-rs1693482 & A-A-T-G & $108(0.006)$ & $228(0.018)$ & $0.63(0.03-13.35), 0.179 ; 0.764 ; 0.690$ \\
\hline rs1229984-rs6413413-rs283413-rs1693482 & G-A-G-G & $108(0.013)$ & $228(0.036)$ & $0.55(0.05-5.65), 0.081 ; 0.616 ; 0.682$ \\
\hline rs1229984-rs6413413-rs283413-rs1693482 & A-A-G-G & $108(0.631)$ & $228(0.614)$ & $1.61(0.71-3.64), 0.393 ; 0.253 ; 0.420$ \\
\hline rs1229984-rs6413413-rs283413 & G-A-G & $119(0.015)$ & $230(0.047)$ & $0.27(0.03-2.27), 0.023 ; 0.229 ; 0.420$ \\
\hline rs1229984-rs6413413-rs283413 & A-A-G & $119(0.978)$ & $230(0.926)$ & $7.66(1.56-37.51), 0.002 ; 0.012 ; 0.078$ \\
\hline rs1229984-rs6413413-rs1693482 & G-A-A & $111(0.003)$ & $254(0.014)$ & $3.08 \times 10^{-5}(0.0-0.06), 0.072 ; 0.007 ; 0.078$ \\
\hline rs1229984-rs6413413-rs1693482 & A-A-A & $111(0.347)$ & $254(0.33)$ & $1.03(0.52-2.05), 0.62 ; 0.933 ; 0.723$ \\
\hline rs1229984-rs6413413-rs1693482 & G-A-G & $111(0.013)$ & $254(0.042)$ & $0.08(0.01-1.04), 0.039 ; 0.054 ; 0.114$ \\
\hline rs1229984-rs6413413-rs1693482 & A-A-G & $111(0.636)$ & $254(0.613)$ & $1.53(0.68-3.44), 0.517 ; 0.303 ; 0.440$ \\
\hline rs1229984-rs283413-rs1693482 & A-G-A & $110(0.350)$ & $228(0.324)$ & $1.13(0.50-2.57), 0.346 ; 0.771 ; 0.690$ \\
\hline rs1229984-rs283413-rs1693482 & A-T-G & $110(0.005)$ & $228(0.017)$ & $0.54(0.02-11.87), 0.132 ; 0.697 ; 0.690$ \\
\hline rs1229984-rs283413-rs1693482 & G-G-G & $110(0.011)$ & $228(0.033)$ & $0.66(0.06-7.1), 0.059 ; 0.730 ; 0.690$ \\
\hline rs1229984-rs283413-rs1693482 & A-G-G & $110(0.630)$ & $228(0.607)$ & $1.64(0.72-3.75), 0.344 ; 0.242 ; 0.420$ \\
\hline rs6413413-rs283413-rs1693482 & A-G-A & $113(0.349)$ & $228(0.336)$ & $1.01(0.48-2.14), 0.664 ; 0.979 ; 0.734$ \\
\hline rs6413413-rs283413-rs1693482 & A-T-G & $113(0.007)$ & $228(0.025)$ & $0.05(0.00-0.96), 0.067 ; 0.047 ; 0.114$ \\
\hline rs6413413-rs283413-rs1693482 & A-G-G & $113(0.645)$ & $228(0.639)$ & $1.43(0.64-3.20), 0.745 ; 0.384 ; 0.525$ \\
\hline rs6413413-rs283413 & A-T & $124(0.008)$ & $230(0.037)$ & $0.09(0.01-0.85), 0.036 ; 0.035 ; 0.106$ \\
\hline rs6413413-rs283413 & A-G & $124(0.992)$ & $230(0.963)$ & 9.39 (1.15-76.49), $0.041 ; 0.036 ; 0.106$ \\
\hline rs6413413-rs1693482 & A-A & $117(0.348)$ & $254(0.344)$ & $0.91(0.41-2.00), 0.924 ; 0.807 ; 0.690$ \\
\hline
\end{tabular}


Table 5. Cont.

\begin{tabular}{|c|c|c|c|c|}
\hline $\begin{array}{c}\text { Haplotype } \\
\text { Variant (SVN Id) }\end{array}$ & Genotype & $\begin{array}{c}\text { Cirrhosis Patients: } \\
\text { Number of Total DNA Samples, } \\
\text { (Frequency for Haplotype) }\end{array}$ & $\begin{array}{c}\text { Controls: } \\
\text { Number of Total DNA Samples, } \\
\text { (Frequency for Haplotype) }\end{array}$ & $\begin{array}{l}\text { Haplotype Association Analysis } \\
\text { OR (95\% CI), } P ; P_{a} ; P_{c}\end{array}$ \\
\hline rs6413413-rs1693482 & A-G & $117(0.652)$ & $254(0.656)$ & $1.1(0.50-2.42), 0.917 ; 0.813 ; 0.690$ \\
\hline rs1229984-rs6413413 & G-A & $125(0.016)$ & $258(0.056)$ & $0.09(0.01-0.68), 0.021 ; 0.019 ; 0.078$ \\
\hline rs1229984-rs6413413 & A-A & $125(0.984)$ & $258(0.943)$ & $9.84(1.43-67.57), 0.027 ; 0.020 ; 0.078$ \\
\hline rs283413-rs1693482 & G-A & $115(0.355)$ & $228(0.346)$ & $1.08(0.46-2.55), 0.741 ; 0.861 ; 0.690$ \\
\hline rs283413-rs1693482 & G-G & $115(0.638)$ & $228(0.630)$ & $1.34(0.60-3.00), 0.729 ; 0.477 ; 0.555$ \\
\hline rs1229984-rs283413 & A-T & $138(0.007)$ & $230(0.027)$ & $0.39(0.03-4.40), 0.074 ; 0.447 ; 0.547$ \\
\hline rs1229984-rs283413 & G-G & $138(0.014)$ & $230(0.054)$ & $0.31(0.04-2.56), 0.024 ; 0.276 ; 0.428$ \\
\hline rs1229984-rs283413 & $A-G$ & $138(0.978)$ & $230(0.919)$ & $6.92(1.39-34.35), 0.001 ; 0.018 ; 0.078$ \\
\hline
\end{tabular}

$P_{a}$ values correspond to $p$ values adjusted by gender and age. $P_{c}$ values correspond to $P_{a}$ values corrected for multiple comparisons by using False Discovery Rate analyses. 


\section{Discussions}

Alcohol abuse is causing a wide range of hepatic lesions, alcohol-related liver cirrhosis being the most severe and harmful state, which may be lethal [4]. Present knowledge suggests that the susceptibility of developing alcohol-related liver cirrhosis is determined by environmental and genetic factors. Thus, data from twin studies demonstrate the heritability of alcohol dependence and its consequences [5]. The study of variations in genes coding for alcohol metabolizing enzymes could lead to a better understanding of the susceptibility and etiopathogenesis of alcohol-related liver cirrhosis. Thus, we analyzed the association between $A D H 1 A, A D H 1 B, A D H 1 C$, and CYP2E1 genetic variants and cirrhosis liver disease in a well-characterized cohort of Spanish patients.

Our results suggest that genetic variation in two genes coding for ethanol-metabolizing enzymes, $A D H 1 B$ and $A B H 1 C$, are related to a lower risk of developing alcohol-related liver cirrhosis. Herein, we described for the first time that $A D H 1 A$ gene deletions were more common in alcohol-related liver cirrhosis patients compared to healthy subjects. Concerning ADH1B SNV, rs1041969 and rs2066702 were monomorphic, which is in agreement with the low allele frequency for individuals with European descent (equal to 0.000 and 0.004 , respectively, in Southern Europeans according the gnomAD database; https:/ / gnomad.broadinstitute.org/. Accessed on 03 February 2021). Also, the observed allele frequencies for $A D H 1 B^{*} 1$ and $A D H 1 B^{*} 2$ in healthy controls were in keeping with those reported in Caucasian subjects [30,46-49]. Moreover, the studies involving the $A D H 1 B$ SNV rs6413413 are scarce. However, the allele frequencies observed in healthy subjects were in concordance with those reported in public databases for Caucasians [50].

Regarding the $A D H 1 B$ rs1229984 (Arg48His) SNV, the $A D H 1 B^{*} 1$ (Arg48, Arg370) allele, which encodes for the $\beta_{1}$ subunit, and the mutated $A D H 1 B^{*} 2$ (His48, Arg370) allele that encodes the subunit $\beta_{2}$, have been described. These two subunits have shown pharmacokinetic differences. The $\beta_{2}$ subunit shows a 20-40-fold higher $V_{\max }$ than the $\beta_{1}$ subunit [10]. Hence, it could be speculated that the association of the variant $A D H 1 B^{*} 2$ allele could be associated with an increased detoxication rate, and hence a lower alcohol exposure. Also, faster ethanol oxidation brings about acetaldehyde accumulation. This fact triggers several unpleasant symptoms including vomiting, headache, and tachycardia. The appearance of these symptoms might act as a disincentive factor to drink alcohol, thereby protecting against ARLDs [5,51]. The ADH1B rs1229984 SNV is prevalent in East Asian individuals but is rare in non-Asians [52]. However, the mutated ADH1B*2 (His48, Arg370) allele has been consistently associated with a protector role against ARLDs in East Asians [51], Africans [53] and Europeans [53]. Thus, our findings are in accordance with previous studies in Asians, where the $A D H 1 B^{*} 2$ allele frequency is much higher. Previously, Rodrigo et al. showed that the frequency of the mutated $A D H 1 B$ rs1229984 allele was slightly higher in healthy controls than in alcohol-related liver cirrhosis patients in a Spanish cohort. Nevertheless, this difference was not statistically significant [48]. The lack of association in such study might be due to the small sample size studied. Furthermore, two studies focusing on Spanish men [30] and Spanish women [47] with ARLDs did not find any association of the risk with the SNV rs1229984. However, these two studies analyzed a small and heterogenous alcoholic patients' cohort, which included cirrhosis, steatosis, or chronic hepatitis, thus calling into question the suitability of these studies to detect significant effects.

Concerning the ADH1C gene, the SNVs rs35385902, rs34195308, and rs35719513 frequencies observed in our study agree with the extremely rare occurrence of these SNVs in Caucasians according to public databases [54] and with the frequencies described in the gnomAD database, that were equal to $0.001,0.000$, and 0.001 for the above-mentioned SNVs, respectively. Also, the association studies including the polymorphism rs 283413 Gly78X are very sparse. However, the allelic frequency observed in the healthy control cohort was shown in correspondence with the British and Irish population [55]. The occurrence of the mutated $A D H 1 C$ rs283413 allele (Arg78) was statistically significantly higher in healthy controls than in alcohol-related liver cirrhosis patients. It should be stated, 
however, that the statistical significance of this association is lower than that observed for $A D H 1 B$ rs1229984, the statistical significance after multivariate logistical regression is marginal (Table 4), the SNVs ADH1C rs283413 and ADH1B rs1229984 are at linkage disequilibrium in all populations $\left(\mathrm{D}^{\prime}=0.967\right)$, and the linkage is even higher in the Iberian population in Spain $\left(\mathrm{D}^{\prime}=1.000\right)$ according to the Linkage Disequilibrium Pair Tool ( https: / /ldlink.nci.nih.gov. Accessed on 27 January 2021). Therefore, it cannot be ruled out that the association of the $A D H 1 C$ rs 283413 SNV with the risk of developing cirrhosis might actually be due to such a linkage.

Regarding the rest of $A D H 1 C$ SNVs, it has been shown that the $A D H 1 C^{*} 1$ variant allele (Arg272 Ile350) encodes the subunit $\gamma_{1}$ and $A D H 1 C^{*} 2$ (Glu272 Val350) the subunit $\gamma_{2}$. Pharmacokinetic studies demonstrated that subjects carrying $A D H 1 C^{*} 1$ can metabolize ethanol at a much faster rate than carriers of $A D H 1 C^{*} 2$, thus resulting in the rapid formation of acetaldehyde [10]. $A D H 1 C^{*} 1$ has been associated with the risk of developing ARLD in Asians [56,57], where this allelic variant is more prevalent than in Caucasians [30,46,47]. We did not find any association of this genetic variant with alcohol-related liver cirrhosis patients. Our results are consistent with previous studies in Spaniards and Europeans $[30,46,47]$.

$A D H$ gene polymorphisms have been related to the triggering effect of alcohol in migraine attacks [58] and with the risk of developing Parkinson's disease in women [59], which is related to the effect of alcohol consumption in Parkinson's disease [60] and with other movement disorders [61].

Regarding CYP2E1, we analyzed the variant CYP2E1*5B rs3813867 (-1295G > C). The genotype frequencies were in correspondence with those described for previous studies in the Spanish population [30] and were similar to the frequencies described in other Caucasian populations $[29,31]$. This gene variant is located at the 5 'regulatory region, and the mutated CYP2E1*5B allele, rs3813867 (-1295C), is associated with higher transcription and increased enzyme activity $[62,63]$. The mutant CYP2E1*5B rs3813867 $(-1295 \mathrm{C})$ variant has been associated consistently associated with ARLDs in Asians $[26,27,63]$. Nevertheless, contradictory results have been reported in Caucasians. Whereas several studies have described this association [29,31,62], other studies did not confirm such association $[30,38,47,48]$. Our results are in agreement with reports showing no association. Further research is needed to confirm the role of CYP2E1*5B in Caucasians patients.

$\mathrm{CNVs}$ are an important source of variations in the human genome that can affect gene expression by a simple gene-dose effect or can include duplication or deletion of gene regulatory regions [64]. We report for the first time the frequencies for $A D H 1 A, A D H 1 B$, $A D H 1 C$, and CYP2E1 CNVs in a Spanish cohort of alcohol-related liver cirrhosis patients and in healthy subjects. Our findings show that $A D H 1 A$ CNVs occur at a higher frequency in alcohol-related liver cirrhosis subjects, although the multivariate regression analysis did not reach statistical significance. Further research is needed to explore the clinical relevance of this finding.

We acknowledge the limitation of the patient cohort sample size, which is relatively small considering that the frequency of some of the SNVs analyzed is very low in the population analyzed. In addition, patient and healthy cohorts have demonstrated significant differences in terms of age, gender, or alcohol consumption. To overcome these limitations, comparisons were adjusted for age and gender. However, a limitation still remains because of the lack of heavy drinkers in the control group. Since heavy alcohol consumption is related to the ARLD etiopathogenesis, different alcohol drinking habits between both cohorts may be expected [3]. Besides, this case-control design has been successfully carried out in previous studies to identify genetic risk factors associated to alcohol-related liver cirrhosis [65-67]. Concerning the age and gender differences shown between alcohol-related liver cirrhosis patients and controls, all the analyses have been adjusted by these cofounding factors to control possible bias.

In summary, our results show that there is an association between functional SNVs in genes involved in ethanol metabolism and alcohol-related liver cirrhosis. Our findings on 
$A D H 1 B$ SNVs point to decreased ethanol metabolism as a risk factor of developing alcoholrelated liver cirrhosis. On one hand, decreased metabolism leads to higher exposure to alcohol and, on the other hand, decreased metabolism brings about lower production of ethanol metabolites that evoke unpleasant symptoms. With these unpleasant symptoms reduced, higher ethanol consumption or development of chronic alcohol consumption might be expected.

Author Contributions: P.A., E.G.-M., J.A.G.A. and J.M.L. designed research. J.M.L. evaluated patients and performed clinical research. E.G.-M. and J.A.G.A. selected controls. Conceptualization, P.A., E.G.-M., J.A.G.A. and J.M.L.; Data curation, P.A., J.A.G.A. and J.M.L.; Formal analysis, P.A., E.G.-M., J.A.C.-G., J.A.G.A. and J.M.L.; Funding acquisition, P.A., E.G.-M., J.A.G.A. Investigation, P.A., E.G.-M., J.A.C.-G., J.A.G.A. and J.M.L.; Methodology, P.A., E.G.-M.; Project administration, J.A.G.A.; Resources, E.G.-M. and J.A.G.A.; Supervision, P.A., E.G.-M., J.A.G.A. and J.M.L.; Validation, J.A.G.A. and J.M.L.; Writing—original draft, P.A., E.G.-M., J.A.G.A. and J.M.L.; Writing-review \& editing, P.A., E.G.-M., J.A.G.A. and J.M.L. All authors reviewed and contributed to the manuscript. All authors have read and agreed to the published version of the manuscript.

Funding: The present study has been supported in part by Grants PI15/00303, PI18/00540, and RETICS ARADyAL RD16/0006/0004 from Fondo de Investigación Sanitaria, Instituto de Salud Carlos III, Madrid, Spain, and IB16170 and GR18145 from Junta de Extremadura, Spain. Financed in part with FEDER funds from the European Union. P. A. holds a "Atracción y retorno de talento investigador" grant by Junta de Extremadura, Spain: TA18025.

Institutional Review Board Statement: The study was conducted according to the guidelines of the Declaration of Helsinki and approved by the Institutional Ethics Committee of the participating hospitals, University Hospital Infanta Cristina (Badajoz, Spain) and San Carlos University Hospital (Madrid, Spain).

Informed Consent Statement: Informed consent was obtained from all subjects involved in the study.

Conflicts of Interest: The authors declare no conflict of interest.

\section{References}

1. Griswold, M.G.; Fullman, N.; Hawley, C.; Arian, N.; Zimsen, S.R.M.; Tymeson, H.D.; Venkateswaran, V.; Tapp, A.D.; Forouzanfar, M.H.; Salama, J.S.; et al. Alcohol Use and Burden for 195 Countries and Territories, 1990-2016: A Systematic Analysis for the Global Burden of Disease Study 2016. Lancet 2018, 392, 1015-1035. [CrossRef]

2. World Health Organization. Available online: https://www.who.int/substance_abuse/publications/global_alcohol_report/en/ (accessed on 13 November 2020).

3. Lieber, C.S. Alcoholic Fatty Liver: Its Pathogenesis and Mechanism of Progression to Inflammation and Fibrosis. Alcohol 2004, 34, 1-19. [CrossRef]

4. Liangpunsakul, S.; Haber, P.; McCaughan, G.W. Alcoholic Liver Disease in Asia, Europe, and North America. Gastroenterology 2016, 150, 1786-1797. [CrossRef]

5. Stickel, F.; Moreno, C.; Hampe, J.; Morgan, M.Y. The Genetics of Alcohol Dependence and Alcohol-Related Liver Disease. J. Hepatol. 2017, 66, 195-211. [CrossRef]

6. Teschke, R. Alcoholic Steatohepatitis (ASH) and Alcoholic Hepatitis (AH): Cascade of Events, Clinical Aspects, and Pharmacotherapy Options. Expert Opin. Pharmacother. 2018, 19, 779-793. [CrossRef] [PubMed]

7. Teschke, R. Microsomal Ethanol-Oxidizing System: Success Over 50 Years and an Encouraging Future. Alcohol. Clin. Exp. Res. 2019, 43, 386-400. [CrossRef] [PubMed]

8. Teschke, R. Alcoholic Liver Disease: Alcohol Metabolism, Cascade of Molecular Mechanisms, Cellular Targets, and Clinical Aspects. Biomedicines 2018, 6, 106. [CrossRef] [PubMed]

9. Crabb, D.W.; Matsumoto, M.; Chang, D.; You, M. Overview of the Role of Alcohol Dehydrogenase and Aldehyde Dehydrogenase and Their Variants in the Genesis of Alcohol-Related Pathology. Proc. Nutr. Soc. 2004, 63, 49-63. [CrossRef] [PubMed]

10. Lee, S.L.; Höög, J.O.; Yin, S.J. Functionality of Allelic Variations in Human Alcohol Dehydrogenase Gene Family: Assessment of a Functional Window for Protection against Alcoholism. Pharmacogenetics 2004, 14, 725-732. [CrossRef] [PubMed]

11. Singal, A.K.; Bataller, R.; Ahn, J.; Kamath, P.S.; Shah, V.H. ACG Clinical Guideline: Alcoholic Liver Disease. Am. J. Gastroenterol. 2018, 113, 175-194. [CrossRef]

12. Choudhary, N.S.; Duseja, A. Genetic and Epigenetic Disease Modifiers: Non-Alcoholic Fatty Liver Disease (NAFLD) and Alcoholic Liver Disease (ALD). Transl. Gastroenterol. Hepatol. 2021, 6, 2. [CrossRef] 
13. Chamorro, A.J.; Torres, J.L.; Mirõn-Canelo, J.A.; González-Sarmiento, R.; Laso, F.J.; Marcos, M. Systematic Review with MetaAnalysis: The I148M Variant of Patatin-like Phospholipase Domain-Containing 3 Gene (PNPLA3) Is Significantly Associated with Alcoholic Liver Cirrhosis. Aliment. Pharmacol. Ther. 2014, 40, 571-581. [CrossRef]

14. Stickel, F.; Buch, S.; Lau, K.; Zu Schwabedissen, H.M.; Berg, T.; Ridinger, M.; Rietschel, M.; Schafmayer, C.; Braun, F.; Hinrichsen, H.; et al. Genetic Variation in the PNPLA3 Gene Is Associated with Alcoholic Liver Injury in Caucasians. Hepatology 2011, 53, 86-95. [CrossRef]

15. Krawczyk, M.; Rau, M.; Schattenberg, R.M.; Bantel, H.; Pathil, A.; Demir, M.; Kluwe, J.; Boettler, T.; Lammert, F.; Geier, A.A. Combined Effects of the PNPLA3 Rs738409, TM6SF2 Rs58542926, and MBOAT7 Rs641738 Variants on NAFLD Severity: A Multicenter Biopsy-Based Study. J. Lipid Res. 2017, 58, 247-255. [CrossRef]

16. Pingitore, P.; Pirazzi, C.; Mancina, R.M.; Motta, B.M.; Indiveri, C.; Pujia, A.; Montalcini, T.; Hedfalk, K.; Romeo, S. Recombinant PNPLA3 Protein Shows Triglyceride Hydrolase Activity and Its I148M Mutation Results in Loss of Function. Biochim. Biophys. Acta Mol. Cell Biol. Lipids 2014, 1841, 574-580. [CrossRef]

17. Kumari, M.; Schoiswohl, G.; Chitraju, C.; Paar, M.; Cornaciu, I.; Rangrez, A.Y.; Wongsiriroj, N.; Nagy, H.M.; Ivanova, P.T.; Scott, S.A.; et al. Adiponutrin Functions as a Nutritionally Regulated Lysophosphatidic Acid Acyltransferase. Cell Metab. 2012, 15, 691-702. [CrossRef]

18. He, S.; McPhaul, C.; Li, J.Z.; Garuti, R.; Kinch, L.; Grishin, N.V.; Cohen, J.C.; Hobbs, H.H. A Sequence Variation (I148M) in PNPLA3 Associated with Nonalcoholic Fatty Liver Disease Disrupts Triglyceride Hydrolysis. J. Biol. Chem. 2010, 285, 6706-6715. [CrossRef]

19. Buch, S.; Stickel, F.; Trépo, E.; Way, M.; Herrmann, A.; Nischalke, H.D.; Brosch, M.; Rosendahl, J.; Berg, T.; Ridinger, M.; et al. A Genome-Wide Association Study Confirms PNPLA3 and Identifies TM6SF2 and MBOAT7 as Risk Loci for Alcohol-Related Cirrhosis. Nat. Genet. 2015, 47, 1443-1448. [CrossRef] [PubMed]

20. Martínez, C.; Galván, S.; Garcia-Martin, E.; Ramos, M.I.; Gutiérrez-Martín, Y.; Agúndez, J.A.G. Variability in Ethanol Biodisposition in Whites Is Modulated by Polymorphisms in the ADH1B and ADH1C Genes. Hepatology 2010. [CrossRef]

21. Hurley, T.D.; Edenberg, H.J. Genes Encoding Enzymes Involved in Ethanol Metabolism. Alcohol Res. Curr. Rev. 2012, 34, 339-344.

22. Lieber, C.S. Alcohol and the Liver: 1994 Update. Gastroenterology 1994, 106, 1085-1105. [CrossRef]

23. Takahashi, T.; Lasker, J.M.; Rosman, A.S.; Lieber, C.S. Induction of Cytochrome P-4502E1 in the Human Liver by Ethanol Is Caused by a Corresponding Increase in Encoding Messenger RNA. Hepatology 1993, 17, 236-245. [CrossRef]

24. Hayashi, S.I.; Watanabe, J.; Kawajiri, K. Genetic Polymorphisms in the 5'-Flanking Region Change Transcriptional Regulation of the Human Cytochrome P450IIE1 Gene. J. Biochem. 1991, 110, 559-565. [CrossRef]

25. Piao, Y.F.; Li, J.T.; Shi, Y. Relationship between Genetic Polymorphism of Cytochrome P450IIE1 and Fatty Liver. World J. Gastroenterol. 2003, 9, 2612-2615. [CrossRef]

26. Tanaka, F.; Shiratori, Y.; Yokosuka, O.; Imazeki, F.; Tsukada, Y.; Omata, M. Polymorphism of Alcohol-Metabolizing Genes Affects Drinking Behavior and Alcoholic Liver Disease in Japanese Men. Alcohol. Clin. Exp. Res. 1997. [CrossRef]

27. Tsutsumi, M.; Takada, A.; Wang, J.S. Genetic Polymorphisms of Cytochrome P4502E1 Related to the Development of Alcoholic Liver Disease. Gastroenterology 1994, 107, 1430-1435. [CrossRef]

28. Wong, N.A.C.S.; Rae, F.; Simpson, K.J.; Murray, G.D.; Harrison, D.J. Genetic Polymorphisms of Cytochrome P4502E1 and Susceptibility to Alcoholic Liver Disease and Hepatocellular Carcinoma in a White Population: A Study and Literature Review, Including Meta-Analysis. J. Clin. Pathol. Mol. Pathol. 2000, 53, 88-93. [CrossRef]

29. Pirmohamed, M.; Kitteringham, N.R.; Quest, L.J.; Allott, R.L.; Green, V.J.; Gilmore, I.T.; Park, B.K. Genetic Polymorphism of Cytochrome P4502e1 and Risk of Alcoholic Liver Disease in Caucasians. Pharmacogenetics 1995, 5, 351-357. [CrossRef]

30. Vidal, F.; Lorenzo, A.; Auguet, T.; Olona, M.; Broch, M.; Gutiérrez, C.; Aguilar, C.; Estupiñà, P.; Santos, M.; Richart, C. Genetic Polymorphisms of ADH 2, ADH 3, CYP 4502E1 Dra-I and Pst-I, and ALDH 2 in Spanish Men: Lack of Association with Alcoholism and Alcoholic Liver Disease. J. Hepatol. 2004, 41, 744-750. [CrossRef]

31. Cichoz-Lach, H.; Partycka, J.; Nesina, I.; Celiński, K.; Słomka, M. The Influence of Genetic Polymorphism of CYP2E1 on the Development of Alcohol Liver Cirrhosis. Wiad. Lek. 2006, 59, 757-761.

32. Sebat, J.; Lakshmi, B.; Troge, J.; Alexander, J.; Young, J.; Lundin, P.; Månér, S.; Massa, H.; Walker, M.; Chi, M.; et al. Large-Scale Copy Number Polymorphism in the Human Genome. Science 2004, 305, 525-528. [CrossRef]

33. Sulovari, A.; Liu, Z.; Zhu, Z.; Li, D. Genome-Wide Meta-Analysis of Copy Number Variations with Alcohol Dependence. Pharm. J. 2018, 18, 398-405. [CrossRef] [PubMed]

34. Rodríguez-López, J.; Flórez, G.; Blanco, V.; Pereiro, C.; Fernández, J.M.; Fariñas, E.; Estévez, V.; Gómez-Trigo, J.; Gurriarán, X.; Calvo, R.; et al. Genome Wide Analysis of Rare Copy Number Variations in Alcohol Abuse or Dependence. J. Psychiatr. Res. 2018, 103, 212-218. [CrossRef] [PubMed]

35. Ulloa, A.E.; Chen, J.; Vergara, V.M.; Calhoun, V.; Liu, J. Association between Copy Number Variation Losses and Alcohol Dependence across African American and European American Ethnic Groups. Alcohol. Clin. Exp. Res. 2014, 38, 1266-1274. [CrossRef]

36. Agúndez, J.A.G.; Ladero, J.M.; Olivera, M.; Lozano, L.; Fernández-Arquero, M.; de la Concha, E.G.; Díaz-Rubio, M.; Benítez, J. N-Acetyltransferase 2 Polymorphism Is Not Related to the Risk of Advanced Alcoholic Liver Disease. Scand. J. Gastroenterol. 2002, 37, 99-103. [CrossRef] [PubMed] 
37. Oliver, J.; Agúndez, J.A.G.; Morales, S.; Fernández-Arquero, M.; Fernández-Gutierrez, B.; de la Concha, E.G.; Díaz-Rubio, M.; Martín, J.; Ladero, J.M. Polymorhisms in the Transforming Growth Factor-B1 Gene (TGF-B1) and the Risk of Advanced Alcoholic Liver Disease. Liver Int. 2005, 25, 935-939. [CrossRef] [PubMed]

38. Agúndez, J.; Ladero, J.; Díaz-Rubio, M.; Benítez, J. Rsa I Polymorphism at the Cytochrome P4502E1 Locus Is Not Related to the Risk of Alcohol-Related Severe Liver Disease. Liver 1996, 16, 380-383. [CrossRef]

39. Gullstén, H.; Agúndez, J.A.G.; Benítez, J.; Läärä, E.; Ladero, J.M.; Díaz-Rubio, M.; Fernandez-Salguero, P.; Gonzalez, F.; Rautio, A.; Pelkonen, O.; et al. CYP2A6 Gene Polymorphism and Risk of Liver Cancer and Cirrhosis. Pharmacogenetics 1997, 7, 247-250. [CrossRef]

40. Ladero, J.M.; Fernández-Arquero, M.; Tudela, J.I.; Agúndez, J.A.G.; Díaz-Rubio, M.; Benítez, J.; de La Concha, E.G. Single Nucleotide Polymorphisms and Microsatellite Alleles of Tumor Necrosis Factor Alpha and Interleukin-10 Genes and the Risk of Advanced Chronic Alcoholic Liver Disease. Liver 2002, 22, 245-251. [CrossRef]

41. Ladero, J.M.; Martínez, C.; García-Martin, E.; Fernández-Arquero, M.; López-Alonso, G.; de La Concha, E.G.; Díaz-Rubio, M.; Agúndez, J.A.G. Polymorphisms of the Glutathione S-Transferases Mu-1 (GSTM1) and Theta-1 (GSTT1) and the Risk of Advanced Alcoholic Liver Disease. Scand. J. Gastroenterol. 2005, 40, 348-353. [CrossRef]

42. Ayuso, P.; Agúndez, J.A.G.; Alonso-Navarro, H.; Martínez, C.; Benito-León, J.; Ortega-Cubero, S.; Lorenzo-Betancor, O.; Pastor, P.; López-Alburquerque, T.; García-Martín, E.; et al. Heme Oxygenase 1 and 2 Common Genetic Variants and Risk for Essential Tremor. Medicine 2015, 94, e968. [CrossRef]

43. Purcell, S.; Neale, B.; Todd-Brown, K.; Thomas, L.; Ferreira, M.A.R.; Bender, D.; Maller, J.; Sklar, P.; de Bakker, P.I.W.; Daly, M.J.; et al. PLINK: A Tool Set for Whole-Genome Association and Population-Based Linkage Analyses. Am. J. Hum. Genet. 2007, 81, 559-575. [CrossRef]

44. Sepanlou, S.G.; Safiri, S.; Bisignano, C.; Ikuta, K.S.; Merat, S.; Saberifiroozi, M.; Poustchi, H.; Tsoi, D.; Colombara, D.V.; Abdoli, A.; et al. The Global, Regional, and National Burden of Cirrhosis by Cause in 195 Countries and Territories, 1990-2017: A Systematic Analysis for the Global Burden of Disease Study 2017. Lancet Gastroenterol. Hepatol. 2020, 5, 245-266. [CrossRef]

45. Edenberg, H.J. The Genetics of Alcohol Metabolism: Role of Alcohol Dehydrogenase and Aldehyde Dehydrogenase Variants. Alcohol Res. Health 2007, 30, 5-13. [PubMed]

46. Borràs, E.; Coutelle, C.; Rosell, A.; Fernández-Muixi, F.; Broch, M.; Crosas, B.; Hjelmqvist, L.; Lorenzo, A.; Gutiérrez, C.; Santos, M.; et al. Genetic Polymorphism of Alcohol Dehydrogenase in Europeans: The ADH2*2 Allele Decreases the Risk for Alcoholism and Is Associated with ADH*3. Hepatology 2000, 31, 984-989. [CrossRef] [PubMed]

47. Lorenzo, A.; Auguet, T.; Vidal, F.; Broch, M.; Olona, M.; Gutiérrez, C.; López-Dupla, M.; Sirvent, J.J.; Quer, J.C.; Santos, M.; et al. Polymorphisms of Alcohol-Metabolizing Enzymes and the Risk for Alcoholism and Alcoholic Liver Disease in Caucasian Spanish Women. Drug Alcohol Depend. 2006, 84, 195-200. [CrossRef]

48. Rodrigo, L.; Alvarez, V.; Rodriguez, M.; Pérez, R.; Alvarez, R.; Coto Garcia, E. N-Acetyltransferase-2, Glutathione S-Transferase M1, Alcohol Dehydrogenase, and Cytochrome P450IIE1 Genotypes in Alcoholic Liver Cirrhosis: A Case-Control Study. Scand. J. Gastroenterol. 1999, 34, 303-307. [CrossRef] [PubMed]

49. He, L.; Deng, T.; Luo, H.S. Genetic Polymorphism in Alcohol Dehydrogenase 2 (ADH2) Gene and Alcoholic Liver Cirrhosis Risk. Int. J. Clin. Exp. Med. 2015, 8, 7786-7793.

50. Gene [ADH1B]. National Center for Biotechnology Information. Bethesda, MD, USA, (NCBI). Available online: https://www. ncbi.nlm.nih.gov/SNP / snp_ref.cgi?locusId=125 (accessed on 17 November 2020).

51. Li, D.; Zhao, H.; Gelernter, J. Strong Association of the Alcohol Dehydrogenase 1B Gene (ADH1B) with Alcohol Dependence and Alcohol-Induced Medical Diseases. Biol. Psychiatry 2011, 70, 504-512. [CrossRef]

52. Osier, M.; Pakstis, A.J.; Kidd, J.R.; Lee, J.F.; Yin, S.J.; Ko, H.C.; Edenberg, H.J.; Lu, R.B.; Kidd, K.K. Linkage Disequilibrium at the ADH2 and ADH3 Loci and Risk of Alcoholism. Am. J. Hum. Genet. 1999, 64, 1147-1157. [CrossRef]

53. Bierut, L.J.; Goate, A.M.; Breslau, N.; Johnson, E.O.; Bertelsen, S.; Fox, L.; Agrawal, A.; Bucholz, K.K.; Grucza, R.; Hesselbrock, V.; et al. ADH1B Is Associated with Alcohol Dependence and Alcohol Consumption in Populations of European and African Ancestry. Mol. Psychiatry 2012, 17, 445-450. [CrossRef] [PubMed]

54. Gene [ADH1C]. National Center for Biotechnology Information. Bethesda, MD, USA, (NCBI). Available online: https:/ /www. ncbi.nlm.nih.gov/SNP / snp_ref.cgi?locusId=126 (accessed on 19 November 2020).

55. Way, M.; McQuillin, A.; Saini, J.; Ruparelia, K.; Lydall, G.J.; Guerrini, I.; Ball, D.; Smith, I.; Quadri, G.; Thomson, A.D.; et al. Genetic Variants in or near Adh1b and Adh1c Affect Susceptibility to Alcohol Dependence in a British and Irish Population. Addict. Biol. 2015, 20, 594-604. [CrossRef]

56. Yamauchi, M.; Maezawa, Y.; Mizuhara, Y.; Ohata, M.; Hirakawa, J.; Nakajima, H.; Toda, G. Polymorphisms in Alcohol Metabolizing Enzyme Genes and Alcoholic Cirrhosis in Japanese Patients: A Multivariate Analysis. Hepatology 1995, 22, $1136-1142$. [CrossRef]

57. Chao, Y.-C.; Liou, S.-R.; Chung, Y.-Y.; Tang, H.-S.; Hsu, C.-T.; Li, T.-K.; Yin, S.-J. Polymorphism of Alcohol and Aldehyde Dehydrogenase Genes and Alcoholic Cirrhosis in Chinese Patients. Hepatology 1994, 19, 360-366. [CrossRef] [PubMed]

58. García-Martín, E.; Martínez, C.; Serrador, M.; Alonso-Navarro, H.; Navacerrada, F.; Agúndez, J.A.G.; Jiménez-Jiménez, F.J. Alcohol Dehydrogenase 2 Genotype and Risk for Migraine. Headache 2010, 50, 85-91. [CrossRef] 
59. García-Martín, E.; Diez-Fairen, M.; Pastor, P.; Gómez-Tabales, J.; Alonso-Navarro, H.; Alvarez, I.; Cárcel, M.; Aguilar, M.; Agúndez, J.A.G.; Jiménez-Jiménez, F.J. Association between the Missense Alcohol Dehydrogenase Rs1229984T Variant with the Risk for Parkinson's Disease in Women. J. Neurol. 2019, 266, 346-352. [CrossRef] [PubMed]

60. Jiménez-Jiménez, F.J.; Alonso-Navarro, H.; García-Martín, E.; Agúndez, J.A.G. Alcohol Consumption and Risk for Parkinson's Disease: A Systematic Review and Meta-Analysis. J. Neurol. 2019, 266, 1821-1834. [CrossRef] [PubMed]

61. Jiménez-Jiménez, F.J.; Gómez-Tabales, J.; Alonso-Navarro, H.; Zurdo, M.; Turpín-Fenoll, L.; Millán-Pascual, J.; Adeva-Bartolomé, T.; Cubo, E.; Navacerrada, F.; Rojo-Sebastián, A.; et al. Association between the Rs1229984 Polymorphism in the Alcohol Dehydrogenase 1B Gene and Risk for Restless Legs Syndrome. Sleep 2017, 40. [CrossRef]

62. Grove, J.; Brown, A.S.J.M.; Daly, A.K.; Bassendine, M.F.; James, O.F.W.; Day, C.P. The RsaI Polymorphism of CYP2E1 and Susceptibility to Alcoholic Liver Disease in Caucasians: Effect on Age of Presentation and Dependence on Alcohol Dehydrogenase Genotype. Pharmacogenetics 1998, 8, 335-342. [CrossRef]

63. Khan, A.J.; Ruwali, M.; Choudhuri, G.; Mathur, N.; Husain, Q.; Parmar, D. Polymorphism in Cytochrome P450 2E1 and Interaction with Other Genetic Risk Factors and Susceptibility to Alcoholic Liver Cirrhosis. Mutat. Res. Fundam. Mol. Mech. Mutagenesis 2009, 664, 55-63. [CrossRef] [PubMed]

64. Henrichsen, C.N.; Chaignat, E.; Reymond, A. Copy Number Variants, Diseases and Gene Expression. Hum. Mol. Genet. 2009, 18, R1-R8. [CrossRef] [PubMed]

65. García-Bañuelos, J.; Panduro, A.; Gordillo-Bastidas, D.; Gordillo-Bastidas, E.; Muñoz-Valle, J.F.; Gurrola-Díaz, C.M.; Sánchez-Enríquez, S.; Ruiz-Madrigal, B.; Bastidas-Ramírez, B.E. Genetic Polymorphisms of Genes Coding to AlcoholMetabolizing Enzymes in Western Mexicans: Association of CYP2E1*c2/CYP2E1*5B Allele with Cirrhosis and Liver Function. Alcohol. Clin. Exp. Res. 2012, 36, 425-431. [CrossRef] [PubMed]

66. Kim, M.S.; Lee, D.H.; Kang, H.S.; Park, H.S.; Jung, S.; Lee, J.W.; Kwon, K.S.; Kim, P.S.; Kim, H.G.; Shin, Y.W.; et al. Genetic Polymorphisms of Alcohol-Metabolizing Enzymes and Cytokines in Patients with Alcohol Induced Pancreatitis and Alcoholic Liver Cirrhosis. Korean J. Gastroenterol. Taehan Sohwagi Hakhoe Chi 2004, 43, 355-363. [PubMed]

67. Trépo, E.; Gustot, T.; Degré, D.; Lemmers, A.; Verset, L.; Demetter, P.; Ouziel, R.; Quertinmont, E.; Vercruysse, V.; Amininejad, L.; et al. Common Polymorphism in the PNPLA3/Adiponutrin Gene Confers Higher Risk of Cirrhosis and Liver Damage in Alcoholic Liver Disease. J. Hepatol. 2011, 55, 906-912. [CrossRef] 